\title{
O PAPEL DE SÍLVIA LANE NA MUDANÇA \\ DA PSICOLOGIA SOCIAL DO BRASIL
}

\author{
Iray Carone \\ Universidade de São Paulo, São Paulo, Brasil
}

\begin{abstract}
RESUMO: As memórias de um período de mudanças implantadas na Psicologia Social da Pontifícia Universidade Católica de São Paulo, durante os anos 80, quando Sílvia Lane enfatizou os compromissos éticos e políticos da Psicologia com a realidade brasileira.
\end{abstract}

PALAVRAS-CHAVE: Sílvia Lane, Psicologia Social e Realidade Brasileira, Escola de Frankfurt.

\section{THE ROLE OF SÍLVIA LANE IN THE CHANGE OF BRAZILIAN SOCIAL PSYCHOLOGY}

ABSTRACT: The memoirs of the 80's Social Psychology under the influence of Sílvia Lane at the Pontificia Universidade Católica de São Paulo, when she emphasized its ethical and political commitments with Brazilian reality.

KEYWORDS: Sílvia Lane, Social Psychology and Brazilian Reality, The Frankfurt School.

Quando participei da celebração dos 30 anos de vida do programa de Psicologia Social da PUCSP em 13 de março de 2002, tive a oportunidade de reafirmar um vínculo que nunca se desfez com esse programa de pósgraduação, acompanhando não só o seu desenvolvimento ao longo do tempo como a sua consolidação de centro produtor de conhecimento no Brasil.

Trabalhei no programa, como professora do quadro permanente, desde o primeiro semestre de 1978 até o primeiro semestre de 1987, ou seja, durante nove anos. Depois desse período, me desliguei da PUCSP para ingressar na Universidade de São Paulo, embora tenha mantido uma ligação profunda com o programa até os dias de hoje.

Desde 1969, pertencia ao quadro do Departamento de Filosofia da PUCSP, como professora de Lógica Matemática e Filosofia das Ciências. Tinha, além disso, vínculos com os departamentos de Letras da Faculdade de Comunicação, Letras e Filosofia, pois ensinava lógica aplicada às linguagens naturais em razão da necessidade de um certo domínio do simbolismo lógico para a compreensão das gramáticas transformacionais ou gramáticas gerativas que predominavam nos currículos da época. Na década de 70, a lingüística da PUCSP era considerada a linha de investigação mais avançada do Brasil. Dessa articulação entre a lógica matemática e a linguística, foi extraído o tema de minha tese de Doutoramento, defendida em 1975.

Eu poderia dizer que quando ingressei no programa de Psicologia, entendia razoavelmente de problemas epistemológicos das ciências naturais, das ciências matemáticas e da lingüística. Mas vejo agora que não entendia nada ou entendia muito pouco de psicologia social e de ciências sociais.

Tinha acompanhado, em 1971, um curso da pósgraduação em Psicologia da Universidade de São Paulo, ministrado pelo filósofo Hugh Lacey, sobre a relação entre teoria científica e observação empírica. Como o curso era dirigido para os behavioristas e psicólogos experimentais da USP, considerei a relação entre teoria e observação um tema muito pertinente e necessário para ser introduzido na área de conhecimento em que estava dando os primeiros e inseguros passos. Lembro-me que uma aluna me disse, na época, que a Psicologia Social era uma área de aplicação das teorias psicológicas, ou seja, que não havia nenhuma teoria que lhe fosse própria: um ramo da psicologia.

A disciplina sob a minha responsabilidade se chamava Lógica do Conhecimento Científico. O próprio nome da disciplina atestava a sua orientação neopositivista, pois era extraído da obra de Karl Popper que dizia ser essa a única tarefa da filosofia das ciências: a de descobrir a lógica ou estrutura hipotético-dedutiva das teorias científicas, pois só com essa estrutura as teorias poderiam verificar a validade de suas predições. Teorias sem essa estrutura eram consideradas não-científicas, pré-científicas ou pseudocientíficas. A epistemologia de Popper, como a de outros neopositivistas, era normativa e internacionalmente dominante nos manuais e cursos de filosofia das ciências, embora tivesse começado a ser abalada pelos estudos de história das ciências de Thomas Kuhn. (Kuhn;1975)

Além do mais, tinha sido rigorosamente enfrentada e discutida por Theodor W. Adorno nos anos 60, durante 
a chamada "disputa entre o positivismo e a dialética nas ciências sociais" (Adorno; 1980).

O programa de Psicologia Social, sob a coordenação e a inspiração da professora Sílvia Tatiana Maurer Lane, começou a colocar em questão não só o positivismo da Psicologia Social de extração norte-americana que prevalecia no Brasil, mas também a orientação clínica e o caráter a-histórico das abordagens do objeto da Psicologia em geral. Nos finais dos anos 70, foi incluída no programa de Pós-Graduação, a disciplina Psicologia Social e Realidade Brasileira, que cunhava o novo sentido da Psicologia Social: (1) o reconhecimento do caráter social e histórico do psiquismo e do comportamento humanos; (2) a necessidade de se voltar a atenção para as chamadas questões nacionais, como já acontecera com as Ciências Sociais no Brasil; (3) a necessidade de não se perder a especificidade do objeto da Psicologia, embora se reconhecendo o primado do todo social sobre as partes, ou da sociedade sobre o indivíduo; (4) a necessidade de se escolher as questões ou problemas de relevância social e política para o Brasil e América Latina.

É importante observar que essa disciplina cumpriu um papel crucial no desenvolvimento do programa como um todo. Era a porta de entrada para o novo universo de investigações, com um enfoque que não só respeitava as diretrizes gerais para a história e para as questões nacionais, mas também e, sobretudo, para as linhas de pesquisa que estavam sendo traçadas. Ficou sob a responsabilidade de Antonio da Costa Ciampa, que ao longo do tempo, em conjunto com quase uma centena de mestrandos e doutorandos, passou a aprofundar a categoria de Identidade dentro de uma perspectiva teórica que retrata mais um dos aportes de Sílvia Lane à Psicologia Social. Bader Sawaia, por sua vez, também desenvolveu mais uma linha de pesquisa sobre a Afetividade, sob a inspiração direta dos estudos de Sílvia Lane a respeito das categorias atividade, consciência e afetividade dos marxistas Leontiev e Vygostski. Essas duas linhas de pesquisa, definidas pelas marcas da reflexão desses dois intelectuais e seus muitos orientandos, formam hoje o principal legado de Sílvia Lane à Psicologia Social brasileira.

Acredito que nem sempre as coisas foram assim tão claras para todos nós: não podemos esquecer que esta é uma visão retrospectiva e muito pessoal daquilo que estava acontecendo nos anos 80; em última análise, o programa de Psicologia Social, sob a batuta de Sílvia Lane, estava muito mais preocupado com as mudanças de conteúdo da Psicologia Social e suas decorrências metodológicas, ou seja, com mudanças ontológicas, epistemológicas e políticas, do que com mudanças formais na grade curricular. Além disso, não havia uma indicação expressa em buscar no marxismo o solo privilegiado para dar a grande guinada ontológica, mesmo porque a obra clássica de Marx (Marx;1978) não comportava e não expunha nenhuma teoria psicológica, embora fosse baseada numa antropologia crítica e filosófica do trabalho alienado.

Relembrando a observação daquela aluna, feita durante o meu primeiro curso de Lógica do Conhecimento Científico, diria que a Psicologia Social hoje deixou de ser vista como um ramo menor da psicologia, para encarnar a própria essência da psicologia, na medida em que o psiquismo humano, dentro da postura históricosocial, é tomado como uma formação dialeticamente determinada pelo processo de socialização, ou seja, que os processos psicológicos, internos ou externalizados pelo comportamento humano, não são independentes e separados da vida social. Fazia pleno sentido, então, repetir com Freud, que "a psicologia individual, num sentido ampliado, mas inteiramente justificável das palavras, é, ao mesmo tempo, psicologia social" (Freud; 1972: p. 91).

Nas discussões então empreendidas houve a participação ativa de psicólogos pós-graduandos advindos, de modo geral, da Universidade Mogi das Cruzes (dentre os quais, o nosso professor Odair Sass), que eram extremamente politizados e envolvidos no combate à ditadura militar implantada no Brasil e com o processo urgente da redemocratização do aparelho de Estado. Os professores de Psicologia Social da Universidade de Mogi das Cruzes, é bom lembrar, eram professores da Pontifícia Universidade Católica de São Paulo que guardavam uma estreita relação com Sílvia Lane.

O Setor de Pós-Graduação da PUCSP passava, então, por um processo de mudanças em grande parte determinado pela presença de grandes sociólogos e pensadores marxistas do Brasil, tais como Octávio Ianni, Florestan Fernandes, Paul Singer, Francisco de Oliveira, Cândido Procópio e José Arthur Giannotti. Banidos da universidade pública pela ditadura militar no Brasil encontraram naquele Setor um abrigo e um lugar extremamente aberto para dar continuidade ao seu trabalho de intelectuais e militantes socialistas. Como era um setor concentrado no quarto andar do Prédio Novo, a convivência dos pesquisadores, docentes e alunos era muito intensa e propiciava um clima altamente favorável para a reflexão política sobre as ciências humanas e a sociedade brasileira. Os alunos de Psicologia Social freqüentavam as disciplinas dos sociólogos, especialmente Teorias Sociológicas de Octávio Ianni, trazendo questões novas para a Psicologia, nas salas de aulas e nos projetos de pesquisa de Mestrado e Doutorado.

Por outro lado, os pós-graduandos de Ciências Sociais passaram também a frequientar as salas de aulas 
dos cursos de Psicologia Social, interessados na nova abordagem instaurada no período.

Foram anos de viragem, como eu costumo nomear, os anos em que as portas abertas para a discussão do objeto, do método e da orientação política no programa de Psicologia Social foram para valer. No entanto, corríamos riscos: de um lado, procurar respostas prontas nas Ciências Sociais e acabar fazendo uma espécie de sociologização da Psicologia; de outro, abandonar métodos e técnicas de pesquisa acumulados nas investigações psicológicas, que ainda chamávamos, de modo muito impreciso, de positivismo, sem inventar outros recursos para tratar histórica e socialmente um objeto de natureza histórica e social. Falava-se muito de método dialético e de materialismo histórico, mas a tradição da psicologia brasileira era ainda muito alheia ao pensamento marxista. (Quando o programa começou a se desenvolver dentro de uma nova baliza, não só incorporou a teoria crítica da Escola de Frankfurt, mas também outras variantes do marxismo, tais como os soviéticos Leontiev e Vygostski, e os neomarxistas Agnes Heller e Habermas. Essa abertura foi, sem dúvida, mais uma das facetas da postura de Sílvia Lane para provocar as mudanças necessárias ao desenvolvimento da Psicologia Social no Brasil).

Comecei a estudar o assunto mais a fundo, a despeito de minha formação ter sido muito distanciada da literatura marxista. Em 1979, coloquei como tema dos cursos de Lógica do Conhecimento Científico, a critica ideológica das ciências. Em 1981, tematizei as concepções de ideologia, marxistas e não-marxistas. Em 1983, tratei da questão da heteronomia do sujeito, do ponto de vista marxista A partir de 1984, dei os primeiros cursos sobre teoria crítica da Escola de Frankfurt e empreendi com os alunos uma leitura sistemática de $A$ personalidade autoritária (Adorno; 1950), obra imensa escrita por Theodor W. Adorno e vários pesquisadores da Universidade da Califórnia em Berkeley. Em 1985, no Doutorado em Psicologia Social, apresentei um curso sobre a crise da dialética no pensamento ocidental e a necessidade de um esclarecimento filosófico sobre a dialética não-clássica de Theodor W. Adorno.(Adorno;1950)

A preocupação, em todos esses cursos, era a de não perder, de maneira alguma, o objeto específico da Psicologia com a finalidade de não escorregar numa visão sociologista do psiquismo, tomando, como supostos básicos: (1) a primazia do todo social sobre o indivíduo, e (2) o conteúdo e a função social da nossa organização psicológica.

A teoria crítica da Escola de Frankfurt me parecia atender, de modo decisivo, a esses dois requisitos, embora fosse considerada, por alguns militantes marxistas da época, um hegelianismo de esquerda e a desistência distópica da luta política pela transformação social. Diziam, pejorativamente, que o próprio nome de Adorno mostrava para o que ele servia: de mero "adorno"...

Creio que os processos históricos, depois dos anos 70 , responderam eficazmente a esses equívocos. Quem há de negar, hoje, a importância política dos textos frankfurtianos sobre a massificação social, o preconceito racial, a canibalização da cultura pela indústria cultural, o fascismo subterrâneo e latente das sociedades democráticas ocidentais? Não havia, então, um conteúdo político avançado nas suas análises quase proféticas sobre as tendências objetivas das sociedades ocidentais, assinaladas desde os anos 30 ?

Além disso, para ampliar os meus conhecimentos, estagiei em 1985 na Universidade de Berkeley para estudar com o historiador da Escola de Frankfurt, Martin Jay. Desse contato com Jay, resultou um trabalho publicado em edição pré-print pela editora da PUCSP em 1987. Foi republicado, anos mais tarde, numa antologia de psicologia política da Editora Cortez . (Carone; 1995)

Eu diria, hoje, que o período de mutação do programa de Psicologia Social, no qual entrei de modo desprevenido, foi a melhor experiência que tive na minha vida. Abri os olhos para a sociedade na qual vivia e adquiri a autoconsciência de minha posição política como professora e pesquisadora na Universidade. É por esse motivo que devo tanto a este programa e a Sílvia Lane, sua criadora, cuja influência foi tão decisiva quanto permanente.

Creio que existe uma boa reciprocidade, pois estou sempre voltando para cá. No primeiro semestre de 2000, por exemplo, fui convidada para ministrar um curso sobre a questão dos paradigmas na Psicologia, de acordo com a filosofia das ciências historicamente orientada de Thomas Kuhn. No segundo semestre, um outro sobre as epistemologias clássicas. Não deixei de destacar, nesses cursos, entretanto, o quociente ideológico das teorias epistemológicas, que não são, de modo algum, tão isentas quanto aparentam ser.

Continuo a viver sob o impacto e a inspiração daqueles anos tão corajosos, verdadeiro marco no destino da Psicologia Social no Brasil. Ainda hoje, a minha pesquisa versa sobre a relação da teoria crítica com a pesquisa empírica na Psicologia.

Para dar seqüência aos estudos iniciados nos anos 80, fiz estágio de pós-doutorado em Nova York, na trilha da produção de Theodor W. Adorno durante o seu exílio norte-americano de 1938 a 1950. Coletei, no estágio de abril a junho de 2001, as fontes primárias, os dados da produção de Adorno sobre a música no rádio, quando participou do chamado Princeton Radio Research Project. Eles ainda estão parcialmente arquivados nos setores especializados das bibliotecas da Universidade 
de Columbia. Outros foram publicados apenas nos anos 40. Mas dada a sua importância, alguns estão saindo dos arquivos e publicados em edições cuidadosas de musicólogos contemporâneos.

A pesquisa sobre o projeto de Princeton não tem apenas interesse histórico, como um episódio da história das ciências sociais aplicadas ao estudo do rádio enquanto um meio de comunicação de massas. As análises da música no rádio, realizadas por Adorno, assinalam o momento inicial de sua crítica da indústria cultural, antes mesmo de ela ser assim nomeada. A fisiognomia do rádio (Adorno; 2006), como Adorno preferiu denominar o seu estudo, descreve elementos objetivos (sociais, políticos, econômicos) sem dissociá-los dos elementos subjetivos e psicológicos. Assim, juntamente com a sua análise do fetichismo na música pela forma-mercadoria, ele empreendeu o estudo dos seus efeitos psicossociais, sobretudo da regressão da audição.

É interessante observar que quando fui para Berkeley em 1985, procurei em vão um especialista de teoria crítica da Escola de Frankfurt que pertencesse ao Departamento de Psicologia. Aquilo me soou estranho, pois a pesquisa sobre a personalidade autoritária havia sido realizada naquela importante universidade. Mais estranho ainda quando constatei que nos anos 50 e 60 os psicólogos sociais norte-americanos haviam feito uso intensivo de suas escalas atitudinais e publicado os resultados nas mais importantes revistas de Psicologia. Por essa razão, a minha pesquisa foi realizada no Departamento de História, sob a orientação de Martin Jay, internacionalmente conhecido pelos estudos sobre a emigração intelectual alemã nos Estados Unidos. Isso indicava que, pelo menos nos Estados Unidos, a Escola de Frankfurt era assunto de interesse histórico, mas sem significação para os psicólogos dos anos 80.

No programa de Psicologia Social, graças às mudanças implantadas por Sílvia Lane, a Escola de Frankfurt (juntamente com as outras vertentes do marxismo já mencionadas) ganhou um lugar real e muitas pesquisas avançaram nessa direção. Quando Sílvia leu, pela primeira vez, o meu relatório da pesquisa realizada em Berkeley, nós estávamos ministrando um curso de especialização em Campo Grande. Após a leitura, me disse que a Escola de Frankfurt era uma grande contribuição à psicologia social, principalmente porque o marxismo clássico e o marxismo ortodoxo haviam desconhecido o novo poder de massificação da industria cultural e, sob a sua influência, a possibilidade sempre presente de irrupções de grupos fascistas nas sociedades capitalistas e democráticas do mundo ocidental.

Anos antes, no entanto, me dissera que via "muito positivismo" no uso das escalas de atitude e na quantificação de resultados de entrevistas de modelo clínico de
A personalidade autoritária. Depois da leitura do relatório, entretanto, reconheceu que essas estratégias metodológicas não comprometiam, de modo algum, as conclusões críticas dessa grande obra.

Certamente, concluo eu, os diagnósticos dessa pesquisa se provaram verdadeiros: a perseguição às atividades anti-nortemericanas pela comissão do senador Joseph McCarthy, de 1950 a 1954, durante os anos da Guerra Fria, e os conflitos violentíssimos que ocorreram na década de 60, quando os negros lutaram pelos seus direitos civis, mostraram de modo evidente não só a intolerância e o ódio racial, mas também a paranóia social contra os suspeitos de comunismo e ideologias socialistas num país com instituições democráticas. Por maiores e fundamentadas que sejam as críticas epistemológicas a essa obra, ela foi a primeira a deixar evidente, pelos pontos de suas escalas, o fascismo latente dessa sociedade.

O que poderemos, então, dizer do Brasil? Estaremos nós, indivíduos pertencentes a uma sociedade dita cordial, imunes às ideologias fascistas?

Finalizando, gostaria de enfatizar a importância do programa de Psicologia Social da PUCSP para a renovação política dessa área de conhecimento sem o aprisionamento em sectarismos doutrinários, tornando a Psicologia uma ciência humana comprometida ética e politicamente com a mudança dos aspectos irracionais, injustos e antidemocráticos da sociedade brasileira.

\section{Referências Bibliográficas}

Adorno, Th. W. Current of music: elements of a radio theory. Frankfurt: Suhrkamp, 2006.

Adorno, Th. W. Introdução à controvérsia sobre o positivismo na sociologia alemã. IN: Textos escolhidos: Walter Benjamin, Max Horkheimer, Theodor W. Adorno, Jurgen Habermas. São Paulo: Abril Cultural (Os Pensadores), (1980) p. $209-257$.

Adorno, Th. W.; Frenkel-Brunswik, E.; Levinson, D. J.; \& Stanford, N. The authoritarian personality: studies on prejudice. Nova York: Harper and Brothers (1950).

Carone, I. Teoria Crítica e Psicologia Social: o impacto do Instituto de Pesquisa Social sobre a investigação psicossocial. IN: Azevedo, M. A. \& Menin, M. S.(orgs). Psicologia e Política: reflexões sobre possibilidades e dificuldades deste encontro. São Paulo: Cortez Ed. /Fapesp (1995), p. 57-114.

Freud, S. Psicologia de grupo e a análise do ego Rio de Janeiro: Imago (1972) p. 91.

Marx. K. El capital: crítica de la economia política. México: Fondo de Cultura Económica (1978).

Kuhn. Th. S. A estrutura das revoluções científicas. São Paulo: Perspectiva (1975). 
Iray Carone é bacharel e licenciada em Filosofia; Doutora em Filosofia pela PUC-SP; Pós-Doutorados como Visiting Scholar na Universidade da Califórnia (Berkeley), na Universidade de Columbia (Nova York) e

New School for Social Research (Nova York);

Pesquisadora contratada pela Universidade Paulista. Endereço para correspondência:

Universidade de São Paulo, Cidade Universitária Armando de Sales Oliveira, Butantã, São Paulo, SP,

05508-900.

iraycarone@uol.com.br

\section{O Papel de Sílvia Lane na Mudança da Psicologia} Social do Brasil

Iray Carone

Recebido: 24/05/2007

$1^{a}$ revisão: 14/09/2007

Aceite final: 14/09/2007 